\title{
BENTUK SAPAAN KEKERABATAN BAHASA SULA DALAM \\ PERSPEKTIF GENDER
}

\section{KINDSHIP IN SULA LANGUAGE FROM GENDER PERSPECTIVE}

\author{
Nurhayati Fokkaya \\ Kantor Bahasa Provinsi Maluku Utara \\ Jalan Wijaya Kusuma No. 81, Kota Baru, Temate \\ Telepon 081342251088
}

\begin{abstract}
Abstrak
Dalam perspektif gender BS, terdapat perbedaan bentuk sapaan kekerabatan antara laki-laki dan perempuan pada keluarga inti. Perbedaannya terlihat pada penggunaan pronomina kedua tunggal, yaitu mon "kamu" dan gu "engkau." Bentuk sapaan tersebut hanya berdimensi biasa atau (tidak setara) dan digunakan oleh siapa pun untuk saling menyapa. Perempuan lebih dominan menggunakan sapaan sopan (setara) ketika menyapa laki-laki, seperti sapaan kim 'anda' dan gi 'kalian.' Dalam kekerabatan BS, kata kim dan gi merupakan sapaan yang tinggi statusnya dan sangat sopan apabila diujarkan. Penelitian ini bertujuan untuk mengetahui bentuk sapaan kekerabatan BS pada keluarga inti dalam perspektif gender. Metode yang digunakan dalam penelitian ini adalah metode kualitatif. Selain itu, teknik pengumpulan data dilakukan dengan menggunakan metode menyimak, mendengar, mencatat, dan merekam.
\end{abstract}

Kata kunci: sapaan kekerabatan, bahasa Sula, perspektif gender

Abstract

In gender perspective of Sula language, there is a different form of addressing male and female in nucleus family. This can be seen in the use of second single pronoun mon "you" and gu "you". This kind of addressing covers the usual dimension or (unequal) and is used by anyone. More dominantly, women use polite addressing (equivalent) when greeting men, as in the word kim "you" referred to singular pronoun and gi "you" referred to plural pronoun. In Sula kinship, the word kim and gi are considered to be more prestigious in social status and more polite. This study aims to identify the forms of kinship address in nucleus family from the perspective of gender. This is a qualitative research and the technique of collecting data involves the activities of observing, listening, noting, and recording.

Keywords: kinship addressing, Sula language, gender perspective

\section{Pendahuluan}

Bahasa merupakan sebuah alat perwujudan budaya yang digunakan manusia untuk saling berkomunikasi, baik tulis maupun lisan. Tujuannya untuk menyampaikan maksud atau kemauan kepada orang lain. Melalui bahasa, manusia dapat menyesuaikan diri dengan adatistiadat, tingkah laku, dan tata krama, serta mudah membaurkan diri dengan masyarakat luas.
Bahasa Sula atau selanjutnya disingkat BS merupakan salah satu bahasa daerah yang dituturkan oleh masyarakat Sula, khsusnya suku Fahu, Fagud, dan Fatcei, yang tersebar di wilayah Pulau Mangole dan Pulau Sanana, Kabupaten Kepulauan Sula. BS memiliki bentuk sapaan kekerabatan yang digunakan pada keluarga inti, seperti baba 'ayah,' nyaya 'ibu,' dan gana 'anak.' Sapaan kekerabatan BS digunakan pula pada 
keluarga luas, seperti baba 'ayah,' nyaya 'ibu,' gana 'anak,' fuk 'adik,' kak 'kakak,' nopafina 'nenek,' nopama' ana 'kakek,' tam ma 'ana 'mertua laki-laki,' dan tamfina 'mertua perempuan.'

Selain itu, BS juga merupakan media komunikasi antara sesama yang mencerminkan perbedaan bentuk sapaan pada pronominal (pertama, kedua, atau ketiga), makna (tunggal atau jamak), dan jenis kelamin (laki-laki atau perempuan). Perbedaannya terlihat pada hubungan kekerabatan dalam keluarga inti hingga keluarga luas. Misalnya, istri menyapa suami atau sebaliknya, anak laki-laki menyapa anak perempuan atau sebaliknya, serta laki-laki yang status sosialnya lebih tinggi menyapa perempuan yang status sosialnya lebih rendah atau sebaliknya, dan laki-laki yang usianya lebih tua menyapa perempuan yang usianya lebih muda atau sebaliknya.

Sapaan merupakan sejumlah kata yang digunakan untuk menyapa seseorang. Kata sapaan secara umum memiliki dua fungsi, yaitu menyapa dan menyebut. Fungsi menyapa merupakan penggunaan bentuk kata ganti orang yang diujarkan oleh pembicara secara tidak langsung, misalnya sau 'ipar' dan fungsi menyebut merupakan kata ganti orang yang diujarkan secara langsung dengan menggunakan sebutan nama, misalnya 'Ramna'.

Dalam hal sapaan, ada dua dimensi mendasar pada interaksi personal, yakni dimensi solidaritas dan dimensi kekuatan. Dimensi solidaritas adalah peran atau status sosial pembicara dan lawan bicara asimetris (tidak sopan/tidak setara), yang ditandai dengan huruf $\mathrm{T}$ 'kamu' dan dimensi kekuatan adalah peran atau status sosial pembicara dan lawan bicara simetris (sopan/setara), yang ditandai dengan huruf $\mathrm{V}$ 'anda.'

Kedua dimensi tersebut dibedakan dengan melihat hubungan keakraban dan formalitas dari kedua belah pihak. Hubungan keakraban ialah hubungan seseorang dengan orang lain karena perkawinan, saudara kandung, atau kerabat dekat, sedangkan hubungan formalitas ialah hubungan antara pembicara dengan lawan bicara karena kebiasaan dalam lingkungan setempat, misalnya pembicara menghormati lawan bicaranya ketika menyapa (Broun dan Gilman dalam Kuntjara, 2003: 45).

Hal ini berarti bahwa seseorang yang lebih tinggi status sosialnya akan menyapa dengan sapaan $\mathrm{T}$ kepada yang lebih rendah status sosialnya atau seseorang yang status sosialnya lebih rendah akan menyapa dengan sapaan hormat V kepada orang yang lebih tinggi status sosialnya. Sapaan antara orang-orang yang status sosialnya sama (setara), akan menggunakan sapaan V karena sifatnya menghormati (Broun dan Gilman dalam Kuntjara, 2003: 45).

Agar lebih jelas, perbedaan sistem sapaan berdasarkan status sosial (pekerjaan), usia, dan jenis kelamin dapat dilihat sebagai berikut:

a. apabila suami memiliki status sosial lebih rendah atau lebih tinggi dari sang istri, maka bentuk sapaan istri kepada suami adalah $\mathrm{kim}$ 'anda, dan apabila status sosial istri lebih tinggi (pekerjaan) atau lebih rendah dari sang suami, maka bentuk sapaan suami kepada istri adalah mon 'kamu, '

b. jika suami memanggil istri, maka istri wajib menjawab dengan sapaan jou 'tuan,' tetapi jika istri memanggil suami, maka suami hanya menjawab dengan sebutan nama istri saja, misalnya 'Anì atau kata tanya gowa ‘apa, 'dan

c. anak perempuan selalu menggunakan sapaan tiba `abang,' fuk `adik' kepada saudara lakilaki, tetapi anak laki-laki hanya menggunakan sapaan dengan sebutan nama, seperti `Nia` kepada saudara perempuannya.

Interaksi sapa-menyapa pada uraian tersebut memperlihatkan bahwa sapaan mon 'kamu' dan gu 'engkau' adalah sapaan laki-laki kepada perempuan. Bentuk sapaan mon dan gu bisa 
digunakan oleh pesapa untuk menyapa semua orang dalam bertutur karena sapaan ini bermakna biasa dan bersifat netral. Sementara itu, sapaan 'kim' dan 'gi' bermakna sopan dan memiliki kekuasaan sebab sapaan tersebut hanya dapat dipakai oleh satu pihak (laki-laki).

Deskripsi contoh tersebut, menunjukkan perbedaan bentuk sapaan yang jumlahnya terlihat pada bentuk sapaan perempuan. Perempuan menyapa laki-laki dengan pilihan sapaan yang sopan atau setara agar sapaan tidak mempengaruhi budaya setempat.

Berdasarkan uraian tersebut, masalah dalam tulisan ini adalah bagaimana bentuk sapaan kekerabatan BS pada keluarga inti dalam perspektif gender. Tujuan penelitian ini adalah mengetahui bentuk sapaan kekerabatan BS pada keluarga inti dalam perspektif gender. Manfaat penelitian ini adalah secara teoritis, memperluas wawasan pengetahuan peneliti serta dapat mendukung penelitian sebelumnya pada bidang ilmu bahasa, sedangkan secara praktis dapat digunakan sebagai bahan referensi atau rujukan pada umumnya dan, peneliti bahasa yang dapat meneliti tentang bentuk saapan kekerabatan bahasa Sula dalam objek yang berbeda pada khususnya.

\section{Kerangka teori}

Teori yang digunakan dalam penelitian ini adalah teori sosiolinguistik dengan pendekatan gender. Sosiolinguistik adalah ilmu antardisiplin antara sosiologi dan linguistik, atau dua bidang ilmu yang mempunyai kaitan yang sangat erat. Untuk memahami sosiolinguistik dengan baik, terlebih dulu dijelaskan kedua antardisiplin tersebut.

Sosiologi adalah kajian objektif dan ilmiah mengenai manusia dalam masyarakat, mengenai lembaga-lembaga, dan proses sosial yang berbeda di dalam masyarakat. Sosiologi berusaha mengetahui kondisi masyarakat itu terjadi, berlangsung, dan tetap ada. Dengan mempelajari lembaga-lembaga sosial dan segala masalah sosial dalam suatu masyarakat, akan diketahui tata cara manusia menyesuaikan diri dengan lingkungan, bersosialisasi, dan menempatkan diri pada tempatnya masing-masing di dalam masyarakat. Sementara itu, linguistik adalah bidang ilmu yang mempelajari bahasa atau bidang ilmu yang mengambil bahasa sebagai objek kajiannya. Dengan demikian, sosiolinguistik adalah bidang ilmu antardisiplin yang mempelajari bahasa dalam kaitannya dengan penggunaan bahasa itu di dalam masyarakat (Chaer dan Agustina, 2010: 2).

Gender (Kamusq) adalah suatu konsep kultural yang merujuk pada karakteristik yang membedakan antara wanita dan pria baik secara biologis, perilaku, mentalitas, dan sosial budaya. Pria dan wanita secara seksual memang berbeda. Begitu pula secara perilaku dan mentalitas. Namun, perannya di masyarakat dapat disejajarkan dengan batasan-batasan tertentu.

Selain itu, gender (Fakih dalam Kuntjara, 2003: 10) adalah suatu sifat yang melekat pada kaum laki-laki dan perempuan yang dikonstruksi secara sosial dan kultur, misalnya sifat gender yang melekat pada perempuan yang dikenal lemah, lembut, cantik, emosional atau keibuan, sedangkan laki-laki dinggap kuat, rasional, jantan, dan perkasa.

Perspektif gender adalah konsep yang membedakan antara laki-laki dengan perempuan yang didominasi oleh budaya patriarki, seperti perbedaan peran, perilaku, dan status sosial.

\section{a. Kata sapaan}

Kata sapaan merupakan bentuk pronomina kedua yang bersifat kekerabatan dan lebih ramah dalam berkomunikasi. Sebagai istilah sapaan, kata-kata yang lazim dipakai dalam menyapa adalah bapak, ibu, kakak, bibi, paman, serta pengganti kata aku atau kamu (Chaer, 2003: 5).

Satuan bahasa mempunyai sistem tutur sapa, yakni sistem yang mempertautkan seperangkat kata atau ungkapan yang dipakai untuk menyebut 
para pelaku dalam status peristiwa bahasa. Sapaan merupakan suatu cara penyampaian maksud dari yang menyapa kepada yang disapa, baik secara lisan maupun tulis.

Tutur sapa sebagai suatu sistem untuk menyampaikan maksud mempunyai peranan penting karena sistem sapaan yang berlaku dalam bahasa tertentu berbeda dengan sistem sapaan yang berlaku dalam bahasa lain. Perbedaan itu tidak hanya terdapat pada kosakata sapaan, tetapi juga pada sikap penutur ketika proses sapaan berlangsung.

Adapun klasifikasi sapaan untuk menyebut orang kedua sebagai berikut:

1. kata ganti orang pertama (aku, saya);

2. kata ganti orang kedua (engkau, kamu);

3. nama diri (Mita) atau didahului kata sapaaan (Saudara, Nyonya, Tuan);

4. istilah kekerabatan (kakek, paman, abang);

5. gelar dan pangkat (jenderal, dokter);

6. kata ganti agentif (penonton, pendengar, pemirsa);

7. bentuk nomina+ ku (kekasihku, ibuku);

8. kata-kata diektis atau petunjuk (itu, situ); dan

9. bentuk-bentuk nomina lainnya (bung, anda).

\section{b. Kekerabatan}

Kekerabatan merupakan salah satu hubungan mendasar untuk mengelompokkan tiap orang ke dalam kelompok sosial, peran, kategori, dan silsilah. Hubungan kekerabatan dapat dihadiri secara nyata, misalnya ibu, ayah, kakek, nenek, dan saudara. Tingkat kekerabatan tidak identik dengan pewarisan.

Selain itu, ada pula hubungan kekerabatan atau kekeluargaan yang merupakan hubungan antara entitas yang memiliki asal-usul silsilah yang sama, baik melalui keturunan biologis, sosial, maupun budaya. Silsilah tersebut dapat menggambarkan suatu struktur sosial dari masyarakat yang bersangkutan.

\section{Metode dan Teknik}

Metode yang digunakan dalam penelitian ini adalah metode kualitatif. Metode ini digunakan untuk mendeskripsikan bentuk sapaan kekerabatan BS dalam perspektif gender. Penelitian ini dilakukan semata-mata berdasarkan pada fakta-fakta yang ada atau fenomena yang secara empiris hidup pada penuturnya, sehingga yang dihasilkan atau yang dicatat berupa perian bahasa yang bisa dikatakan potret atau paparan seadanya (Sudaryanto, 1992: 62).

Teknik pengumpulan data yang digunakan adalah metode simak dan metode cakap. Metode simak adalah metode yang digunakan untuk memperoleh data dengan melakukan penyimakan terhadap penggunaan bahasa (Mahsun, 2007:242). Konkretnya dalam metode ini, peneliti menyimak, mendengar, mencatat, dan merekam data yang dituturkan oleh penutur. (Muhammad, 2012:195). Sementara itu, metode cakap adalah melakukan percakapan dengan para informan. Metode cakap ini memiliki teknik dasar berupa teknik pancing yang diikuti dengan teknik lanjutan, yaitu teknik cakap semuka. Pada pelaksanaan teknik cakap semuka ini, peneliti langsung melakukan percakapan dengan pengguna bahasa sebagai informan yang bersumber pada pancingan yang sudah disiapkan berupa daftar pertanyaan atau secara spontanitas, berupa pancingan yang muncul di tengah-tengah percakapan (Mahsun, 2007:250).

Setelah data terkumpul, peneliti melakukan analisis. Kegiatan analisis adalah kegiatan menguraikan, menjabarkan, menyelidiki, memecahkan atau menganalisis permasalahan, dalam hal ini, data penelitian yang telah dikumpulkan dengan menggunakan metode dan teknik tertentu serta berlandaskan pada teori yang sesuai. (Bugin, 2003: 12).

Selain itu, sumber data dalam penelitian ini berupa data primer dan sekunder. Data primer diperoleh melalui wawancara dengan menggunakan pertanyaan langsung dan terarah 
kepada informan, untuk mendapatkan bentukbentuk sapaan dan percakapan penutur. Kemudian, data sekunder diperoleh melalui referensi, baik dalam bentuk skripsi maupun buku bacaan yang berkaitan dengan sapaan kekerabatan dalam bahasa Indonesia pada umumnya dan bahasa daerah setempat pada khususnya.

\section{Pembahasan}

Berikut ini akan dideskripsikan bentuk sapaan kekerabatan BS pada keluarga inti yang menyatakan pronomina berdasarkan situasi pembicara, baik formal maupun informal, yang berdimensi sopan (setara) dan tidak sopan (tidak setara).

\subsection{Bentuk sapaan kekerabatan BS yang menyatakan pronomina (pertama, kedua, dan ketiga) dan jumlah makna (tunggal, jamak)}

Pronomina persona $a k$ 'saya,' digunakan untuk menyebut orang pertama tunggal dalam situasi informal maupun formal yang berdimensi sopan (setara).

Pronomina persona kit 'kita,' digunakan untuk menyapa orang pertama jamak dalam situasi informal yang berdimensi sopan (setara).

Pronomina persona kim 'anda, digunakan untuk menyapa orang kedua tunggal dalam situasi informal yang berdimensi sopan (setara).

Pronomina persona mon 'kamu,' digunakan untuk menyapa orang kedua tunggal dalam situasi informal dan formal yang berdimensi biasa dan tidak sopan (tidak setara).

Pronomina persona $g u$ 'engkau,' digunakan untuk menyapa orang kedua tunggal dalam situasi informal yang berdimensi biasa dan tidak sopan (tidak setara).

Pronomina persona gi 'kalian,' digunakan untuk menyapa orang kedua jamak dalam situasi informal yang berdimensi sopan (setara).
Pronomina persona $k i ` i$ 'dia,' digunakan untuk menyapa orang ketiga tunggal dalam situasi informal yang berdimensi sopan (setara).

Pronomina persona ihi 'mereka, digunakan untuk menyapa orang ketiga jamak dalam situasi informal yang berdimensi sopan (setara).

Berdasarkan bentuk sapaan kekerabatan BS yang menyatakan pronomina di atas, terdapat perbedaan dalam perspektif gender, yaitu sapaan pada penggunaan kata pronomina kedua tunggal mon 'kamu' dan gu 'engkau.' Bentuk sapaan tersebut hanya berdimensi biasa atau tidak sopan (tidak setara) dan digunakan oleh siapa pun untuk saling menyapa.

\subsection{Bentuk sapaan kekerabatan BS yang menyatakan pronomina berdasarkan jenis kelamin (laki-laki atau perempuan), usia, dan status sosial (profesi)}

BS memiliki bentuk sapaan kekerabatan yang terdiri atas baba `ayah, 'nyaya `ibu, kak `kakak, fuk 'adik,' feta 'saudara perempuan,' na` $i$ 'saudara laki-laki, dan tiba ‘kakak laki-laki pertama. Tidak ada sapaan untuk kakak perempuan pertama (-).

Sapaan baba 'ayah' digunakan untuk menyapa orang tua laki-laki pertama tunggal yang usianya lebih tua, misalnya:

(a) Anak : Baba laka awa moya? 'Ayah tidak pergi ke kebun?'

(b) Ayah : Kaka moya, fa kol gan sanang moya iki.

'Tidak pergi, karena tidak enak badan.'

Contoh kalimat (a) menggambarkan seorang anak menyapa ayahnya dengan bentuk sapaan yang sopan dalam situasi informal, seperti $b a b a$ 'ayah,' karena anaknya tidak menyebut nama ayah. Contoh kalimat (b) menggambarkan seorang ayah menyampaikan kondisi kesehatannya kepada anaknya dan tidak 
mencerminkan adanya bentuk sapaan dalam kalimat tersebut.

Sapaan nyaya 'ibu' digunakan untuk menyapa orang perempuan pertama tunggal yang lebih tua, misalnya:

(a) anak : Nyaya bit laka sowa? 'Pergi ke mana ibu?

(b) ibu : Bit laka pasar baha kena. 'Pergi ke pasar belanja ikan.'

Kalimat contoh (a) tentang seorang anak meyapa ibunya dengan bentuk sapaan yang sopan dalam situasi informal, seperti sapaan nyaya ‘ibu, tetapi dalam kalimat (b) tidak menggambarkan tentang bentuk sapaan sebab kalimat tersebut hanya memberi keterangan, seperti 'ibu pergi ke pasar belanja ikan.'

Sapaan kak 'kakak' digunakan untuk menyapa orang pertama tunggal yang lebih tua, misalnya:
(a) Adik : Kak, Ina dina i laka sowa? 'Ina pergi kemana, kakak?
(b) Kakak : Ina laka bo ponoida in uma. 'Ina pergi ke rumah temannya.'

Contoh kalimat (a) menggambarkan bentuk sapaan yang sopan dalam situasi informal, yakni sapaan adik kepada kakaknya, kak 'kakak.' Kemudian pada contoh kalimat (b), kakak menjawab pertanyaan adik dan tidak dibubuhi dengan bentuk sapaan.

Sapaan fuk 'adik' digunakan untuk menyapa orang pertama tunggal yang lebih muda, misalnya:
(a) Andi : Mana ana ma ana han? 'Siapa lelaki itu?
(b) Abi : Mana ak fuk yang koka. 'Itu adik saya yang bungsu'.

Contoh kalimat (a) menggambarkan sebuah percakapan antara Andi dan Abi dan tidak menunjukan bentuk sapaan dalam kalimat tersebut, tetapi dalam contoh kalimat (b) menunjukkan bentuk sapaan yang sopan, seperti fuk 'adik, dalam situasi informal. Artinya, Abi menjawab pertanyaan Andi tentang keberadaan laki-laki di rumahnya itu adalah adiknya yang bungsu.

Sapaan feta 'saudara perempuan' digunakan untuk menyapa orang pertama tunggal (adik perempuan atau kakak perempuan) dalam kekerabatan BS, misalnya:
(a) Ala : Inca, anafina han neka?'Siapa gadis itu, Inca?
(b) Inca : Neka ak feta yang aya. `Saudara perempuan saya yang pertama.'

Contoh kalimat (a) adalah bentuk pertanyaan dan tidak menggambarkan bentuk sapaan, sedangkan kalimat (b) mengandung bentuk sapaan yang berdimensi sopan yang digunakan dalam situasi informal, yakni feta 'saudara perempuan.'

Sapaan na $i$ 'saudara laki-laki' digunakan untuk menyapa orang pertama tunggal (adik lakilaki atau kakak laki-laki) dalam kekerabatn BS, misalnya:

(a) Ima : Ija, kim na `i deha sowa? 'Ija, Saudara laki-laki kamu di mana?'

(b) Ija :akna i sai ambon. 'Saudara lakilaki saya pergi ke Ambon.`

Contoh kaliamat (a) dan (b) menunjukkan bentuk sapaan kekerabatan yang berdimensi sopan dan digunakan dalam situsi informal. Pada kalimat (a), Ima bertanya kepada Ija tentang keberadaan saudara laki-lakinya dengan sapaan na $i$ 'saudara laki-laki' dan Ija menjawab dengan sapaan $n a$ ` $i$ 'saudara laki-laki,' bukan menyebut nama saudara laki-lakinya.

Sapaan tiba 'abang' digunakan untuk menyapa kakak pertama laki-laki dalam kekerabatan BS, misalnya:

(a) Adik perempuan : Tiba, gi laka tora ak bo sekolah dad te moya!

'Abang, boleh antar saya ke sekolah.'

(b) Kakak pertama laki-laki : Gain gu wa ak topi pai.

'Tolong kamu ambilkan topi saya di atas meja. 
Contoh kalimat di atas mendeskripsikan bentuk sapaan kekerabatan yang berdimensi sopan (setara) yang terlihat pada contoh kalimat (a), yakni sapaan tiba ‘abang.' Bentuk sapaan ini digunakan dalam situasi informal. Selain itu, contoh kalimat (b) menggambarkan bentuk sapaan tidak sopan (tidak setara) dalam situasi informal yang digunakan oleh kakak pertama laki-laki kepada adik perempuan, seperti sapaan gu 'engkau.'

Dalam sapaan kekerabatan BS, tidak ditemukan bentuk sapaan untuk menyapa kakak perempuan pertama. Hal ini menjadi diskriminasi bahasa pada perempuan, khusunya dalam hal menyapa. Ketika menyapa, perempuan menggunakan bentuk sapaan yang sopan kepada kakak laki-laki pertama, baik dalam situasi formal maupun informal, sedangkan kakak lakilaki pertama tidak mempunyai pilihan bentuk sapaan untuk menyapa kakak perempuan pertama. Bentuk sapaan kepada perempuan hanya bersifat umum, seperti pada contoh percakapan berikut ini.

(a) Adik laki-laki: Ka Jia, baba laka sowa? 'Kakak Jia, ayah pergi ke mana?

(b) Kakak perempuan pertama: Baba laka wa nui fua.

'Ayah pergi ambil buah kelapa.'

Pada contoh kalimat (a) dan (b) tidak menggambarkan bentuk sapaan khusus untuk menyebut kakak perempuan pertama. Ketika menyapa kakak perempuan, adik laki-laki hanya menyapa dengan sebutan nama yang diikuti dengan sapaan kak, misalnya kak Jia.

\subsection{Faktor-faktor terjadinya perbedaan bentuk sapaan kekerabatan BS dalam perspektif gender}

Berdasarkan bentuk sapaan pronomina dan percakapan di atas, terdapat dikriminasi bentuk sapaan antara laki-laki dan perempuan pada kekerabatan bS dalam perspektif gender.
Perbedaannya tergambar pada pemilihan kata untuk menyapa perempuan, baik dalam situasi formal maupun informal pada keluarga inti.

Perempuan lebih dominan menggunakan sapaan sopan (setara) ketika menyapa laki-laki dan tidak menyebut namanya, seperti kim `anda` dan gi 'kalian'. Dalam kekerabatan BS, kata kim dan $g i$ merupakan sapaan yang tinggi statusnya dan sangat sopan. Namun, sapaan tersebut hanya berlaku pada laki-laki ketika perempuan menyapanya. Hal ini disebabkan oleh faktor kebiasaan dan tradisi dalam kekerabatan keluarga inti.

Masyarakat Sula, khusunya di daerah pengamatan penelitian ini, di Desa Fuata, Kecamatan Sulabesi Selatan, Kabupaten Kepulauan Sula menganut tradisi budaya patriarki. Dalam tradisi tersebut, perempuan (baik kecil, dewasa, atau maupun seorang istri) dalam kekerabatan keluarga inti harus dibiasakan untuk menjunjung tinggi tradisi. Tradisi ini bersifat abstrak karena hanya berupa sikap yang diterapkan secara turun-temurun. Penerapannya sejak usia dini, seperti pada sikap kebiasaan berikut.

Sejak kecil, perempuan mendapatkan teguran lebih apabila dibandingkan dengan lakilaki. Misalnya, apabila anak perempuan duduk tidak sopan atau aktif berbicara dengan orang lain, maka orang tua menegurnya secara langsung dengan alasan bahwa perempuan harus duduk dengan sopan dan tidak boleh terlalu aktif berbicara di depan umum. Akan tetapi, apabila anak laki-laki melakukan hal tersebut, maka diberi pujian.

Kebiasaan atau tradisi ini merupakan faktor utama terjadinya perbedaan antara laki-laki dan perempuan, bukan hanya pada hubungan strata sosial, melainkan pula pada segi penggunaan bahasa. Ketika berbicara, perempuan selalu menjaga tuturan, sikap, dan gaya bahasanya. Selain itu, perempuan harus bersuara lembut 
ketika menyapa seseorang agar tidak dipandang tidak sopan.

Kesopanan dalam tulisan ini dideskripsikan sebagai sebuah kesetaraan antara laki-laki dan perempuan, baik dari segi pekerjaan, pengucapan, maupun tingkah laku (sikap).

\section{Simpulan}

Dalam bentuk sapaan kekerabatan BS, terdapat perbedaan antara sapaan perempuan dengan lakilaki pada keluarga inti. Perbedaannya terlihat pada bentuk sapaan pronomina kedua, seperti mon 'kamu' dan gu 'engkau.' Bentuk sapaan mon 'kamu` dan $g u$ 'engkau' sering digunakan untuk menyapa perempuan, baik kakak perempuan maupun adik perempuan. Selain itu, bentuk sapaan mon dan $g u$ adalah bentuk sapaan yang tidak sopan (tidak setara) yang digunakan dalam situasi informal. Sementara itu, bentuk sapaan untuk menyapa laki-laki mencerminkan bentuk sapaan yang sopan (setara), seperti kim 'anda` dan $g i$ 'kalian.' Hal ini disebabkan oleh faktor kebiasaan dan tradisi dalam keluarga inti secara turun temur, sehingga membentuk karakter kekuasaan yang dominasi oleh laki-laki. Sementara itu, perempuan hanya mempunyai sikap netral atau sikap memilih baik agar tidak melanggar tradisi kekerabatan.

Untuk itu, terdapat deskriminasi bentuk sapaan kekerabatan BS di dalam kelurga inti berdasarkan pandangan gender. Perempuan dimarjinalisasi oleh bentuk sapaan yang disebabkan oleh hubungan struktur sosial dan tradisi budaya dalam keluarga inti yang dibiasakan secara turun-temurun.

\section{Daftar Pustaka}

Bugin, Burhan, 2003. Analisis Data Penelitian Kualitatif. Jakarta: Rineka Cipta.

Chaer, Abdul dan Leonie Agustina. 2004. Sosiolinguistik Perkenalan Awal. Jakarta: Rineka Cipta.
Chaer, Abdul 2007. Pengantar Linguistik Umum. Jakarta: PT Rineka Cipta.

Kutha Ratna, Nyoman. 2004. Teori Metode, dan Teknik Penelitian Sastra.Yogjakarta: Pustaka Pelajar.

Kuntjara, Esther. 2003. Gender Bahasa dan Kekuasaan. Jakarta: PT BPK Gunung Mulia.

Kridalaksana, Harimurti. 2005. Kelas Kata dalam Bahasa Indonesia. Jakarta: PT Gramedia Pustaka Utama.

Mahsun. 2006. Metode Penelitian Bahasa: Tahapan Strategi Metode, dan Tekniknya. Jakarta: PT Raja Grafindo Persada.

Muhammad. 2012. Metode dan Teknik Analisis Data Linguistik. Yogyakarta: Liebe Book Press.

Ollenburger, Jene C. 2002. Sosiologi Wanita. Jakarta: PT Rineka Cipta.

Rakib, Suaiba. 2008. Sistim Sapaan Kekerabatan Dalam Bahasa Tidore. Skripsi Fakultas Sastra dan Budaya, Universitas Khairun Ternate.

Syariah, Pro. 2007. Keadilan dan Kesetaraan Gender. Jakarta: Rineka Cipta.

Saadawi, Nawel El. 2003. Wajah Telanjang Perempuan. Jogjakarta: Pustaka Pelajar.

Wiki. 2016. Hubungan_Kekerabatan. Https://Id.Wikipedia. Tanggal, 20 April 2016.

\section{Sumber internet:}

Kamusq. 2012. Gender-Pengertian-danDefinisi.html. http://www. com. Tanggal, 21 Juni 2016.

Ridanumidarojah. 2016. Kata-Sapaan-Honorfik. Http//Blogspot.Co.Id/2013/05/. Tanggal, 19 Juni 2016. 